\title{
Green synthesis of silver nanoparticles using Azadirachta indica and Ocimum sanctum leaf extract
}

\author{
Sonali Priyadarshini ${ }^{1}$, Sushree Sulava ${ }^{2}$, Rasmita Bhol $^{3}$ and Somanatha Jena ${ }^{1, *}$ \\ ${ }^{1}$ Department of Biotechnology, Rama Devi Women's University, Bhubaneswar 751 022, India \\ ${ }^{2}$ Department of Zoology, College of Basic Science and Humanities, Odisha University of Agriculture and Technology, Bhubaneswar 751 003, India \\ ${ }^{3}$ Department of Life Science, Rama Devi Women's University, Bhubaneswar 751 022, India
}

\begin{abstract}
In the present study, green synthesis of stable silver nanoparticles was done using methanolic leaf extract of Azadirachta indica $\mathrm{L}$. as well as Ocimum sanctum $\mathrm{L}$. The antimicrobial activity was screened against UTI causing bacteria, viz. Escherichia coli, Klebsiella pneumoniae and Staphylococcus aureus using disc diffusion method. Silver nanoparticles derived from tulsi leaf extract inhibited $E$. coli by $12.00 \pm 0.65 \mathrm{~mm}$, $K$. pneumoniae by $9.66 \pm 0.11 \mathrm{~mm}$ and $S$. aureus by $23.00 \pm 0.81 \mathrm{~mm}$ at concentrations $1 \mathrm{mg} / \mathrm{ml}$. Similarly, silver nanoparticles derived from neem leaf extract inhibited $K$. pneumoniae by $9.11 \pm 0.81 \mathrm{~mm}$ and $S$. aureus by $09.0 \pm 1.17 \mathrm{~mm}$ at concentrations $1 \mathrm{mg} / \mathrm{ml}$ respectively. Lower concentration $(1 \mathrm{mg} / \mathrm{ml})$ of tulsi and higher concentration $(4 \mathrm{mg} / \mathrm{ml})$ of neem leaf methanolic extract was observed to be effective against urinary tract infections in human causative agent $S$. aureus.
\end{abstract}

Keywords: Antimicrobial activity, green synthesis, plant extract, silver nanoparticle.

THE genes that couple with silver nanoparticles (AgNPs) have the potential to inhibit cell cycle progression, DNA damage and apoptosis in human cells at non-cytotoxic doses ${ }^{1}$. The mechanisms for AgNPs-induced toxicity include cell membranes, mitochondria and genetic material. When the silver ions enter the bacterial cell, the DNA molecule turns into a condensed form and loses its replication ability leading to bacterial cell death ${ }^{2}$. Some authors have reported that heavy metals inactivate the proteins by getting attached to the thiol group ${ }^{3}$. The nanoparticles release silver ions in bacterial cells, which enhance their bactericidal activity ${ }^{2,4-6}$. The antimicrobial activity of silver has been recorded in early history. Boiled water was stored in silver flagons by the king of Persia while going to war $^{7}$ or the observation that Aspergillus niger could not grow in silver vessels. Nanobiotechnology is at present one of the vibrant disciplines

*For correspondence. (e-mail: somanathjena@gmail.com) of research in contemporary material sciences where plants and plant products find an imperative use in the synthesis of nanoparticles ${ }^{8}$. These particles display entirely novel characteristics such as size, distribution and morphology in comparison to the larger particles of the mass material that they have been prepared from ${ }^{9}$. Silver is preferred as a nanoparticle because of its antibacterial catalytic properties and its non-toxicity towards human health ${ }^{6}$. Green synthesis of AgNPs using different parts of plant extracts has been reported ${ }^{10-15}$. It is preferred over conventional synthesis because it is an eco-friendly, cost-effective, single-step process that can be easily scaled up for large scale production and also does not require high pressure, temperature, energy and toxic chemicals $^{16}$. A lot of work has been done on green synthesis of AgNPs using bacteria, fungi and different plant extracts; because of their anti-oxidant property, they are able of reduce metal compounds into their respective nanoparticle. Plant extracts produce best capping material for stabilization of $\mathrm{AgNPs}^{17}$.

Since ancient times, medicinal plants have been used in India for their ability to act against infectious as well as noninfectious diseases and have been aptly mentioned in Ayurveda. The use of medicinal plants has been increased by traditional medical practitioners for treating various diseases ${ }^{18}$. One such common and important medicinal plant is Ocimum sanctum (commonly known as tulsi) showing anti-microbial, cardio-protective, anti-diabetic, analgesic, anti-spasmodic, anti-emetic, hepato-protective, contraceptive anti-fertility agents, adaptogenic and diaphoretic properties ${ }^{19}$. The active constituent is Eugenol (1-hydroxy-2-methoxy-4-allylbenzene) which is mainly responsible for therapeutic potentials of the cardiovascular system, urinary system, reproductive system, immune system, gastric system, blood biochemistry, and central nervous system and also significant in various ailments in modern medicine ${ }^{20-22}$. Another commonly available medicinal plant is Azadirachta indica (commonly known as neem) a species of the family Meliaceae; each part of this tree has been used as a household remedy for antiquity, treatment against viral, bacterial and fungal infections ${ }^{23}$. Silver nanoparticles can be formed at low concentrations 
of its leaf extract without using any extraneous chemical or physical technique ${ }^{17}$. In the present study, we report the simple synthesis of AgNPs by using Ocimum sanctum and Azadirachta indica leaf methanolic extracts and evaluation of their anti-microbial action against diverse human pathogenic bacteria respectively.

\section{Materials and methods}

\section{Collection of plant materials and preparation of methanolic extracts}

Fresh mature leaves of tulsi (Ocimum sanctum) and neem (Azadirachta indica) were collected from medicinal plant garden, Department of Botany, Rama Devi Women's University, Bhubaneswar campus in February 2018 for preparation of plant extract, evaluation of anti-microbial, anti-oxidative activity and green synthesis of AgNPs.

Grown-up foliage was washed with normal tap water followed by double distilled water to remove the dirt and dust on the surface of the foliage. Roy's method was followed with a slight modification for the extraction process which was carried out from both leaves separately. The wet leaves were weighed on an electronic balance and dried in shade. The dried leaves were cooled at room temperature and weighed again on the same electronic balance. The moisture content of neem and tulsi leaves was calculated using the following equation

$\%$ of moisture content $=\frac{\left[\begin{array}{c}\text { Weight of green leaves }- \\ \text { weight of dry leaves }\end{array}\right]}{\text { Weight of green leaves }} \times 100$.

The leaves were crushed to a fine powder using a mortar and pestle. The air-dried powdered leaf material, $100 \mathrm{~g}$ of neem and $100 \mathrm{~g}$ of tulsi leaves, was extracted with an appropriate volume of methanol separately in $500 \mathrm{ml}$ of complete fitted soxhlet apparatus. Further, both the solutions (solvent and plant extract) were heated for 10 $15 \mathrm{~min}$. The extracts were cooled to make it semi-solid and then stored in a freezer for further use. The solutions (extract and solvent) were used for green synthesis of silver nanoparticles.

\section{Synthesis of silver nanoparticles}

One hundred millilitre of $1 \mathrm{mM}$ silver nitrate (Merck, India) solution was prepared. Then 1,2, 3, 4 and $5 \mathrm{ml}$ of neem and tulsi leaves extract were inoculated individually to $5 \mathrm{ml}$ of silver nitrate solution. This set-up was performed in the dark to reduce photoactivation of silver nitrate at room temperature. The colour changes were observed to confirm the reduction of silver ions ${ }^{10}$.

\section{Test microorganisms}

The pure strain of human pathogen culture Escherichia coli (MTCC 1687), Klebsiella pneumoniae (MTCC 109), Staphylococcus aureus (MTCC 902) were obtained from microbial type culture collection (MTCC) at Chandigarh, India. All the cultures were maintained at $4{ }^{\circ} \mathrm{C}$ in nutrient broth and sub-cultured in nutrient agar (Hi-Media) at regular interval of days. Prior to that, the Petri plates, conical flasks, beakers and the other glassware were cleaned with detergent, autoclaved then dried in a hot air oven.

\section{Anti-oxidant properties of neem and tulsi extract}

The free radical scavenging activity of methanolic extract of $A$. indica and $O$. sanctum was measured by DPPH (2,2-dipheny-1-picryl-hydrazyl) method with slight modifications $^{24,25}$. One $\mathrm{ml}$ of $0.1 \mathrm{mM}$ DPPH solution was added to $1 \mathrm{ml}$ of methanolic extract (test sample) and after $30 \mathrm{~min}$ of incubation, absorbance was measured at $517 \mathrm{~nm}$. The percentage of inhibition was calculated by comparing the absorbance values of the control and test samples. Ascorbic acid was used as a reference (standard). The potential to scavenge DPPH radical was calculated using the equation below.

$$
\% \text { DPPH scavenging activity }=\frac{A_{\text {control }}-A_{\text {test }}}{A_{\text {control }}} \times 100 \text {. }
$$

\section{Disc diffusion method}

The bacterial isolates were screened for antibiotic sensitivity assay by following disc diffusion method ${ }^{26}$. The human pathogens were exposed to different antibiotics such as ampicillin, chloramphenicol, polymyxin B and streptomycin to observe the effect of these antibiotics. Nutrient agar (HIMEDIA) plates were prepared. A sterilized cotton swab was dipped into bacterial suspension ( $24 \mathrm{~h}$ fresh culture) and used to inoculate the whole plane of nutrient agar plate equally. The agar plate was dried for $5 \mathrm{~min}$. The suitable antibiotic discs were dispensed using sterilized forceps. The plates were then instantly incubated in a bacterial incubator at $37^{\circ} \mathrm{C}$ overnight. Post incubation, the diameters of the zones of inhibition were measured in millimeter $(\mathrm{mm})$. Kirby-Bauer test results were interpreted using a table that relates zone diameter to the degree of microbial resistance or sensitivity to the tested antibiotics (Tables 1 and 2; Figures 1 and 2).

\section{Assessment of antimicrobial assay}

Two sets of nutrient agar plates were prepared. In the first set, A, B and C were treated with AgNPs derived from tulsi extract. In the second set, D, E and F were treated with 
Table 1. Anti-bacterial activity of standard antibiotic disc against human pathogenic causing bacteria on nutrient agar plate

\begin{tabular}{lccc}
\hline & \multicolumn{3}{c}{ Inhibition zone $(\mathrm{mm})$} \\
\cline { 2 - 4 } Antibiotics & Escherichia coli & Klebsiella pneumoniae & Staphylococcus aureus \\
\hline Chloramphenicol & $26.00 \pm 0.57^{\mathrm{a}}$ & $12.00 \pm 0.81^{\mathrm{a}}$ & $25.02 \pm 0.66^{\mathrm{a}}$ \\
Streptomycin & $06.00 \pm 0.81^{\mathrm{c}}$ & $02.01 \pm 0.66^{\mathrm{c}}$ & $13.33 \pm 0.55^{\mathrm{d}}$ \\
Ampicillin & $07.66 \pm 1.69^{\mathrm{c}}$ & $07.00 \pm 0.81^{\mathrm{b}}$ & $15.03 \pm 0.54^{\mathrm{c}}$ \\
Polymyxin B & $10.01 \pm 1.08^{\mathrm{b}}$ & $06.00 \pm 0.33^{\mathrm{b}}$ & $17.66 \pm 0.47^{\mathrm{b}}$ \\
\hline
\end{tabular}

Data pooled from a total of three separate experiments each comprising of five replicates on nutrient plate. Mean values within column followed by different alphabets in superscript are significantly different $(P \pm 0.05$; Duncan's new multiple range test).

Table 2. Anti-microbial activity of tulsi and neem leaf metanolic extract against human pathogenic causing bacteria on nutrient agar plate

\begin{tabular}{|c|c|c|c|c|c|c|}
\hline \multirow{2}{*}{$\begin{array}{l}\text { Concentration } \\
(\mathrm{mg} / \mathrm{ml})\end{array}$} & \multicolumn{6}{|c|}{ Inhibition zone (mm) } \\
\hline & \multicolumn{3}{|c|}{ Tulsi leaf extract } & \multicolumn{3}{|c|}{ Neem leaf extract } \\
\hline 1 & $12.00 \pm 0.65^{\mathrm{a}}$ & $09.66 \pm 0.11^{\mathrm{a}}$ & $23.00 \pm 0.81^{\mathrm{a}}$ & - & $09.11 \pm 0.81^{\mathrm{a}}$ & $09.0 \pm 1.17^{\mathrm{b}}$ \\
\hline 4 & $08.76 \pm 0.65^{\mathrm{c}}$ & - & - & $07.88 \pm 0.81^{\mathrm{c}}$ & - & $23.44 \pm 0.47^{\mathrm{a}}$ \\
\hline 5 & $07.76 \pm 0.91^{\mathrm{d}}$ & - & $4.00 \pm 0.81^{\mathrm{c}}$ & - & - & - \\
\hline
\end{tabular}

Data pooled from a total of three separate experiments each comprising of five replicates on nutrient plate. Mean values within column followed by different alphabets in superscript are significantly different $(P \pm 0.05$; Duncan's new multiple range test).
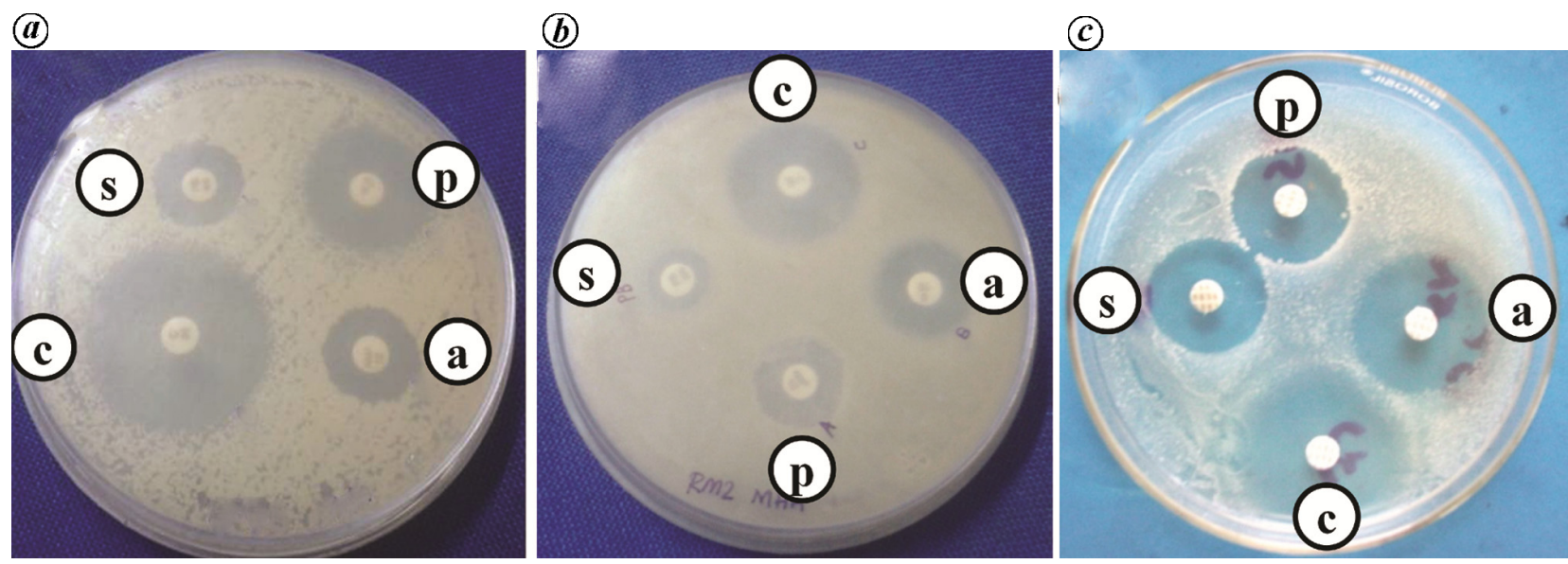

Figure 1. Anti-bacterial activity by disc diffusion method against human urinary tract infection pathogenic bacteria: $\boldsymbol{a}$, Escherichia coli; b, Klebsiella pneumoniae; $\boldsymbol{c}$, Staphylococcus aureus. ('a' ampicillin, 'c' chloramphenicol, 's' streptomycin, 'p' polymyxin B).

AgNPs derived from neem extract. In each Petri plate, 5 wells were bored and respective leaf extract was added ranging from 1, 2, 3, 4 and $5 \mathrm{mg} / \mathrm{ml}$. S5 of AgNPs formed of tulsi leaf extracts and S1 of AgNPs formed of neem leaf extracts were used for anti-microbial assay as the colour formation was deepest in the sample and the UV-Vis spectroscopy showed the highest peak with these samples at $430 \mathrm{~nm}$ (data not shown). A lawn culture of Escherichia coli (MTCC 1687) was streaked on plates A and D, Klebsiella pneumoniae (MTCC 109) on plates B, E and Staphylococcus aureus (MTCC 902) on C and F (Figure 2). The inoculated Petri plates were incubated in a bacterial incubator overnight at $37^{\circ} \mathrm{C}$. The diameter of the clear zone was measured with antibiotic zone scale (expressed in $\mathrm{mm}$ ). The experiments were repeated thrice for each treated sample. 

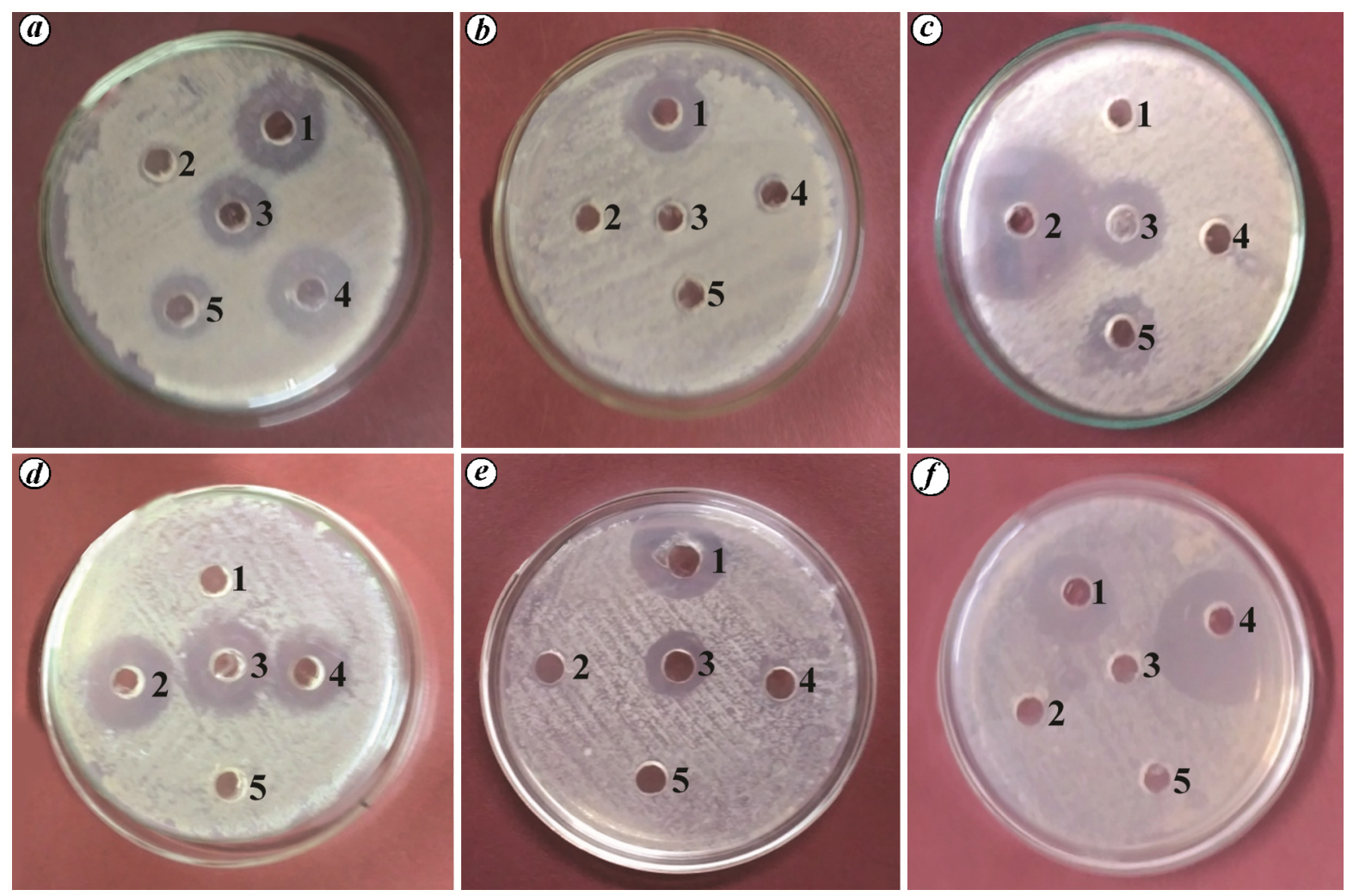

Figure 2. Nutrient agar plates were treated with tulsi methanolic leaves extract against (a) E. coli, (b) K. pneumonia, (c) S. aureus and nutrient agar plates were treated with neem methanolic leaves extract against $(\boldsymbol{d})$ E. coli $(\boldsymbol{e})$ K. pneumoniae and $(f) S$. aureus respectively.

\section{Particle size estimation of AgNPs}

Dynamic light scattering also known as DLS technique (Malvern Instruments) was used to measure the average particle size of the synthesized AgNPs. By this method, the mean size of particles inside the sample can be obtained. It is also possible to find the connection between the number of particles (particular size) and the dimension of the nano-particles.

\section{Results}

\section{Green synthesis and characterization of AgNPs}

The formation of AgNPs by adding silver nitrate solution and leaf-broth was indicated after $2 \mathrm{~h}$ when the colour change was observed. Five extracts of neem (S1-S5) and five extracts of tulsi (S1-S5) were used in AgNPs formation study. The entire set up of neem and tulsi extract with AgNPs formation presented in Figure 3. AgNPs formation in case of tulsi leaf extract had a colour change from pale yellow to deep mustard yellow whereas the neem extract solution became completely dark brown (Figures 3 and 4). In this study, extracts from two plants, neem and tulsi were used to reduce silver ions into
AgNPs. Before that, the moisture content of neem and tulsi leaves was recorded on an experimental basis as 53.26 and 20.11 respectively.

\section{DLS analysis}

The $Z$-average mean (d.nm) of S5 was observed as 174.1 in case of AgNPs formed from tulsi leaf extracts (Figure 5) and in S1, it was measured as 155.4 in case of AgNPs formed from neem leaf extracts (Figure 6). The poly dispersity index (PdI) was 0.354 in $\mathrm{S} 5$ and 0.285 in $\mathrm{S} 1$ sample of AgNPs formed from tulsi and neem leaf extracts respectively. On the whole, the size of the nanoparticle bore good result in both S5 of tulsi and S1 of neem extracts derived AgNPs.

\section{Anti-oxidative activity}

The results are depicted in Table 3. Among the five fractions of extract tested for antioxidant activity, fraction $\mathrm{V}$ of neem showed a maximum antioxidant activity and recorded what $90.65 \%$ compared to standard ascorbic acid that recorded $92.17 \%$ with $R^{2}=0.9986$ and $\mathrm{IC}_{50}=12.45$. The same fraction $\mathrm{V}$ of tulsi extract showed a maximum antioxidant activity and recorded $89.78 \%$ compared to 
standard ascorbic acid that recorded $90.67 \%$ with $R^{2}=0.8749$ and $\mathrm{IC}_{50}=9.84$. Fractions I and II showed very less activity $47.11 \pm 0.89 \%, 59.32 \pm 0.64 \%$ with respect to concentration $1,2 \mathrm{mg} / \mathrm{ml}$ in case of neem leaf extract. It was observed that fraction $\mathrm{V}(5 \mathrm{mg} / \mathrm{ml})$ of both the leaf extracts showed maximum antioxidant activity and percentage is nearer to standard ascorbic acid. The ascending order of anti-oxidative activity of tulsi leaf extracts is $89.78 \pm 0.98 \%, 77.52 \pm 0.81 \%, 69.18 \pm 0.72 \%$, $67.82 \pm 0.61 \%$ and $64.75 \pm 0.52 \%$ with respect to different concentrations of $5,4,3,2,1 \mathrm{mg} / \mathrm{ml}$ respectively, whereas for neem leaf extract, it is $90.65 \pm 0.99 \%, 79.43 \pm$ $1.01 \%, \quad 68.54 \pm 0.98 \%, \quad 59.32 \pm 0.64 \%, \quad 47.11 \pm 0.89 \%$ with respect to same concentrations as tulsi respectively. Both the test samples $\mathrm{V}(5 \mathrm{mg} / \mathrm{ml})$ are equipotent to the standard anti-oxidative compound ascorbic acid (1 mg/ml) (Table 3). Phyto-chemical analysis further needs to be carried out to identify the active principles responsible for antioxidant activity.

\section{Disc diffusion method}

Four different antibiotics such as ampicillin, chloramphenicol, polymyxin $\mathrm{B}$ and streptomycin were used to
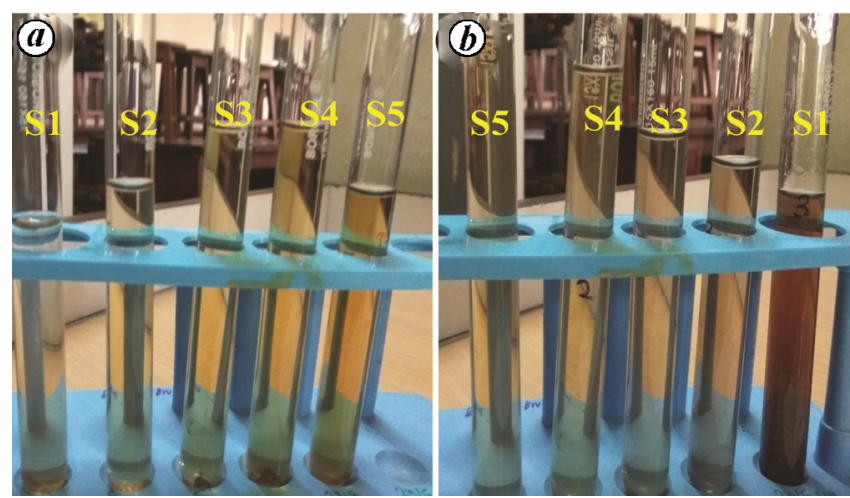

Figure 3. Colour change in the methanolic extracts with silver nitrate after $2 \mathrm{~h}$ incubation of solution. $\boldsymbol{a}$, Tulsi leaf extracts (S1, S2, S3, S4, $\mathrm{S} 5), \boldsymbol{b}$, Neem leaf extracts (S1, S2, S3, S4, S5).

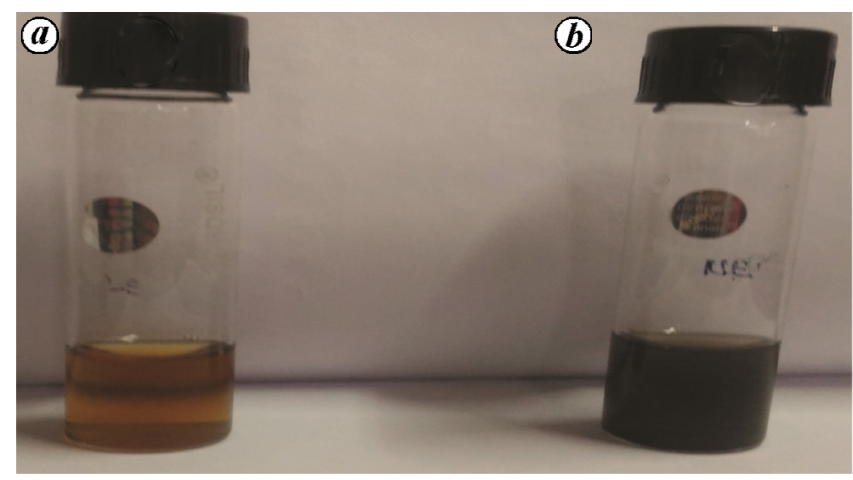

Figure 4. The extract prior to particle size estimation. $\boldsymbol{a}$, Tulsi leaves extract; $\boldsymbol{b}$, Neem leaves extract. observe the effect of these antibiotics. After a $24 \mathrm{~h}$ incubation period, the diameters of the zones of inhibition were measured in mm (Tables 1 and 2). Escherichia coli (MTCC 1687) showed sensitivity to chloramphenicol with the highest zone of inhibition of $26.00 \pm 0.57 \mathrm{~mm}$ diameter whereas Escherichia coli (MTCC 1687) showed resistance to streptomycin with diameter of $06.00 \pm 0.81$, but the intermediate zone of inhibition is $10.01 \pm 1.08$, $07.66 \pm 1.69$ on Escherichia coli inoculated agar plate at concentrations of 4 and $3 \mathrm{mg} / \mathrm{ml}$ respectively. Klebsiella pneumoniae (MTCC 109) showed resistance to streptomycin with a minimum inhibition of $02.01 \pm 0.66$ but showed moderate resistance to chloramphenicol with zone of inhibition $12.00 \pm 0.81$. However, Staphylococcus aureus (MTCC 902) showed sensitivity to the antibiotics chloramphenicol, streptomycin, ampicillin, polymyxin $\mathrm{B}$ with respect to the zone of inhibition as $25.02 \pm 0.66,13.33 \pm 0.55,15.03 \pm 0.54,17.66 \pm 0.47$ respectively (Table 1$)$.

\section{Antimicrobial activity}

Although various concentrations of AgNPs derived from tulsi and neem extract were successful in inhibiting the

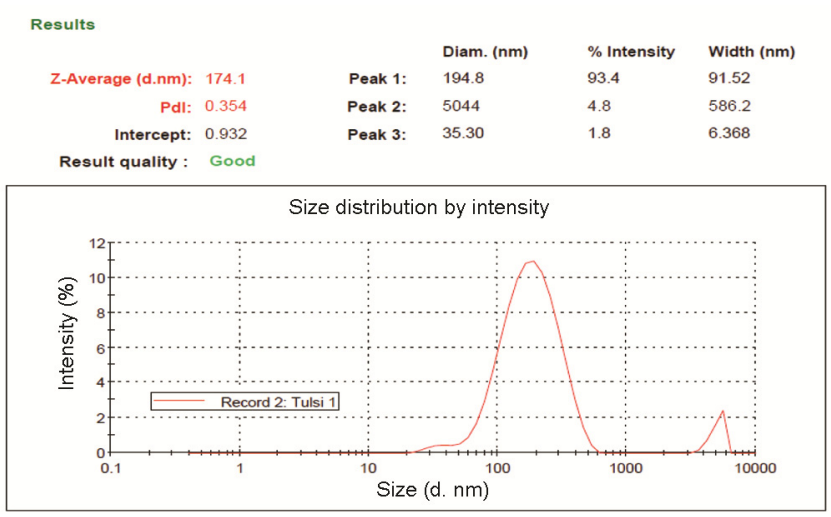

Figure 5. Dynamic light scattering (DLS) result for S5 in case of AgNPs from tulsi methanolic extract.

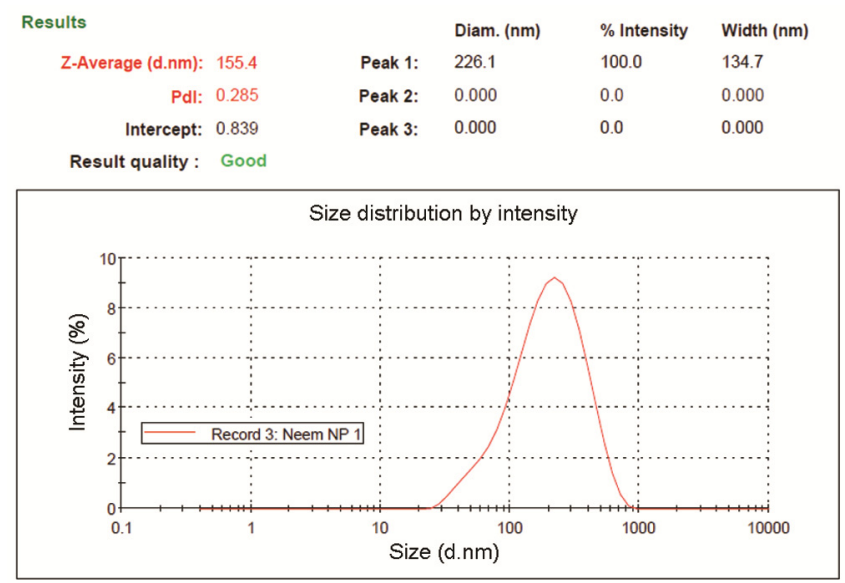

Figure 6. DLS result for $\mathrm{S} 1$ in case of AgNPs from neem methanolic extract. 
RESEARCH ARTICLES

Table 3. DPPH free radical scavenging activity of neem and tulsi leaf methanolic extracts

\begin{tabular}{|c|c|c|c|c|c|}
\hline \multirow{2}{*}{$\begin{array}{l}\text { Concentration } \\
(\mathrm{mg} / \mathrm{ml})\end{array}$} & \multirow[b]{2}{*}{ Samples } & \multicolumn{4}{|c|}{ DPPH free radical scavenging activity (\%) } \\
\hline & & \multicolumn{2}{|c|}{ Neem leaf extract } & \multicolumn{2}{|c|}{ Tulsi leaf extract } \\
\hline 1 & Ascorbic acid & $92.17 \pm 1.23^{\mathrm{a}}$ & & $90.67 \pm 1.02^{\mathrm{a}}$ & \\
\hline 1 & Met. extract & $47.11 \pm 0.89^{\mathrm{f}}$ & & $64.75 \pm 0.52^{\mathrm{f}}$ & \\
\hline 2 & Met. extract & $59.32 \pm 0.64^{\mathrm{e}}$ & $R^{2}=0.9986$ & $67.82 \pm 0.61^{\mathrm{e}}$ & $R^{2}=0.8749$ \\
\hline 3 & Met. extract & $68.54 \pm 0.98^{\mathrm{d}}$ & $\mathrm{IC}_{50}=12.45$ & $69.18 \pm 0.72^{\mathrm{d}}$ & $\mathrm{IC}_{50}=9.84$ \\
\hline 4 & Met. extract & $79.43 \pm 1.01^{\mathrm{c}}$ & & $77.52 \pm 0.81^{\mathrm{c}}$ & \\
\hline 5 & Met. extract & $90.65 \pm 0.99^{b}$ & & $89.78 \pm 0.98^{b}$ & \\
\hline
\end{tabular}

Data pooled from a total of three separate experiments. Mean values within column followed by different alphabets in superscript are significantly different $(P \pm 0.05$; Duncan's new multiple range test).

growth of human pathogens, $1 \mathrm{mg} / \mathrm{ml}$ concentration of tulsi inhibited Staphylococcus aureus (MTCC 902) which when measured was found to be $23.00 \pm 0.81 \mathrm{~mm}$ on agar plate and a concentration of $4 \mathrm{mg} / \mathrm{ml}$ of AgNPs derived from neem extract inhibited the same pathogen by $23.44 \pm 0.47 \mathrm{~mm}$ on agar plate. Both tulsi and neem leaf extracts $(1 \mathrm{mg} / \mathrm{ml}$ and $4 \mathrm{mg} / \mathrm{ml})$ are equipotent to inhibit the growth of Staphylococcus aureus (MTCC 902) on agar plate $(23.00 \pm 0.81,23.44 \pm 0.47)$ however tulsi and neem leaf extracts are moderately potent to inhibit the growth of Escherichia coli and Klebsiella pneumonia on agar plate $(12.00 \pm 0.65,11.00 \pm 0.81,09.00 \pm 0.81$, $08.76 \pm 0.65,07.76 \pm 0.91$ and $09.66 \pm 0.11 ; 10.10 \pm 0.87$, $11.09 \pm 0.77, \quad 07.88 \pm 0.81$ and $09.11 \pm 0.81,04.23 \pm$ 0.22). The data shows that bactericidal potential was more effective against Gram-positive bacteria than Gramnegative bacteria.

\section{Discussion}

Pathogens have always been a serious threat to public health all over the world. In clinical record, Staphylococcus aureus, Escherichia coli and Klebsiella pneumoniae are a world-wide problem. These organisms have been linked to a number of diseases for human beings as well as animals. Many of the pathogens have become antibiotic-resistant like methicillin-resistant Staphylococcus aureus (MRSA): hence fruitful way is needed to control resistant microorganisms worldwide. Now-a-days herbal therapy and nanotechnology are being used to control antibiotic-resistant microorganisms. Synthesis of AgNP using plant extracts has antimicrobial action against Grampositive, Gram-negative bacteria and even against the same multi-drug resistant human pathogens ${ }^{27}$. Silver nanoparticles have been used extensively in the well being industry, drug, fabric-coating, food storage, dye reduction, wound dressing, anti-septic creams and several environmental applications, due to their antimicrobial properties $^{28}$. The stabilization of silver ions by combination with bio-molecules such as proteins, amino acids, enzymes, polysaccharides, alkaloids, tannins, phenolics, saponins, terpenoids and vitamins, which were previously well-known in the plant extracts having therapeutic values, are ecologically benign, yet have chemically composite structure ${ }^{29}$.

The most common technique of DLS is used for characterization of nanoparticles ${ }^{30-32}$. The theory and mathematical basics of DLS technique is previously well known $^{33,34}$. DLS measures the light scattered from the laser that passes through a colloid. The modulation of scattered light intensity as a function of time is analysed, and the hydrodynamic size of particles determined ${ }^{35,36}$. According to ISO 22412 (International Standard ISO 2008), $Z$ average size or $Z$ average diameter is a hydrodynamic parameter and predicts particle shape to be spherical or nearly spherical if we get a monomodal (having only single peak) which has to be further confirmed with TEM analysis. The pdI values less than 0.05 are rarely seen and values greater than 0.7 indicate that the sample has very broad size (Malvern, Instrument manual) ${ }^{1}$. The PdI was 0.354 in S5 and 0.285 in S1 sample of AgNPs formed from tulsi and neem leaf extracts respectively, indicating the quality of nanoparticle to be good. The result corroborates with Roy ${ }^{10}$ whose PdI was below 0.7 for both the samples.

Free radical reactions occur endlessly in each and every cell as part of regular cellular function. However, surplus-free radical creation originating from endogenous or exogenous sources might play a role in several diseases. Anti-oxidants prevent free radical-induced tissue damage by preventing the formation of radicals, scavenging them, or by promoting their breakdown ${ }^{37}$. An antioxidant can be defined as any substance that, when present in low concentrations compared to that of an oxi-disable substrate, significantly delays or inhibits the oxidation of that substrate ${ }^{38}$. The physiological function of antioxidants is to prevent damage of cellular apparatus which arise as a consequence of chemical reactions concerning free radicals. Oxi-dative stress might be important in the pathophysiology of diseases including atherosclerosis, chronic renal failure and diabetes mellitus. A free radical can be a molecular species capable of independent existence that contains an unpaired electron in an atomic 


\section{RESEARCH ARTICLES}

orbital $^{39}$. A majority of significant free radicals in many disease states are oxygen derivatives, particularly superoxide and hydroxyl radical. The plant secondary metabolites such as phenolics and flavonoids are mainly responsible for anti-oxidant activity ${ }^{40}$. They exhibit antioxidant activity by inactivating lipid-free radicals or prevent decomposition of hydro-peroxides into free radicals $^{41}$ or chelate metal ions and protect against pathogens $^{42}$. It has been reported that $A$. indica and $O$. sanctum have anti-oxidant properties. In the present study, neem and tulsi displayed anti-oxidant properties by $90.65 \%$ and $89.78 \%$ on the basis of Table 3 while standard anti-oxidative compound ascorbic acid showed $92.17 \%$. Both leaf extracts show very good free radical scavenging (DPPH) activity, comparable with standard antioxidant compound ascorbic acid.

Neem and tulsi leaf extract mediated silver AgNPs as possible antibacterial agents have been examined in this study. The plant extract mediated AgNPs were tested for individual anti-microbial actions towards both Grampositive ( $S$. aureus) and Gram-negative (E. coli and $K$. pneumoniae) bacterial strains viewing the zones of inhibition $(23.00 \pm 0.81$ and $12.00 \pm 0.65, \quad 09.66 \pm 0.11$; $09.11 \pm 0.81$ and $09.0 \pm 1.17$ ). On the basis of zone of inhibition, synthesized AgNPs prove to exhibit good antibacterial activity which is comparable with standard drug antibiotics (chloramphenicol-26 mm on agar plate). Leaf extract mediated AgNPs were more effective against Gram-positive bacteria $(23.00 \pm 0.81)$ than against Gramnegative ones $(12.00 \pm 0.65,09.66 \pm 0.11)$. According to Ahmed $^{17}$, the $A$. indica aqueous leaf extract AgNPs exhibited good antibacterial activity against $E$. coli and $S$. aureus of $9 \mathrm{~mm}$ each respectively but the methanolic extracts show more antibacterial activity. The mechanism of AgNPs action has been widely studied. Because of their smaller size, AgNPs can easily reach the nuclear content of bacteria. The high concentration of AgNPs is extremely significant and larger surface area shows stronger antibacterial activity ${ }^{12}$. The anti-oxidative activity of $O$. sanctum methanolic leaf extract shows $16.67 \pm 0.577 \mathrm{~mm}$ with respect to $1 \mathrm{mg}$, however our study shows $23.00 \pm 0.81 \mathrm{~mm}$ zone of inhibition with respect to $1 \mathrm{mg}$. So, $O$. sanctum methanolic extract mediated AgNPs show better result than the normal O. sanctum leaf methanolic extract ${ }^{43}$.

\section{Conclusion}

The present study revealed an eco-friendly, economical, rapid, single-step protocol for large scale production of green synthesis of AgNPs with low concentration of methanolic neem and tulsi leaf extracts. AgNPs also showed efficient antimicrobial action against human urinary tract infection causing pathogens like Staphylococcus aureus, Escherichia coli and Klebsiella pneumonia.
Both the leaf extracts showed strong anti-oxidant activity which can be considered a good source of natural antioxidants. Future research could identify secondary metabolites present in both plant extracts which are responsible for mediating the nanoparticle production, antimicrobial and anti-oxidative activity.

Conflict of interest: The authors declare no conflict of interest.

1. Asha Rani, P. V., Hande, M. P. and Valiyaveettil, S., Antiproliferative activity of silver nanoparticles. BMC. Cell. Biol., 2009, 10, 1-14.

2. Feng, Q. L., Wu, J., Chen, G. Q., Cui, F. Z., Kim, T. N. and Kim, J. O., A mechanistic study of the antibacterial effect of silver ions on Escherichia coli and Staphylococcus aureus. J. Biomed. Mater. Res., 2000, 52, 662-668.

3. Liau, S. Y., Read, D. C., Pugh, W. J., Furr, J. R. and Russell, A. D., Interaction of silver nitrate with readily identifiable groups: relationship to the antibacterial action of silver ions. Lett. Appl. Microbiol., 1997, 25, 279-283.

4. Ahamed, M., Al Salhi, S. M. and Siddiqu, M. K. J., Silver nanoparticle applications and human health. Clim. Chim. Acta, 2010, 411, 1841-1848.

5. Swain, P. et al., Antimicrobial activity of metal based nanoparticles against microbes associated with diseases in aquaculture. World J. Microbiol. Biotechnol., 2014, 30, 2491-2502.

6. Rai, M., Yadav, A. and Gade, A., Silver nanoparticles as a new generation of antimicrobials. Biotechnol. Adv., 2009, 27, $76-83$.

7. Blakeney, E. H. (ed.), The History of Herodotus translated by G. Rawlinson, Dent, London, 1945.

8. Banerjee, P., Satapathy, M., Mukhopahayay, A. and Das, P., Leaf extract mediated green synthesis of silver nanoparticles from widely available Indian plants: synthesis, characterization, antimicrobial property and toxicity analysis. Bioresour. Bioprocess, $2014,1,1-10$.

9. Wildenberg, V. and Willems, Roadmap Report on Nanoparticles, W\&W Espana sl, Barcelona, Spain, 2005.

10. Roy, P., Das, B., Mohanty, A. and Mohapatra, S., Green synthesis of silver nanoparticles using Azadirachta indica leaf extract and its antimicrobial study. Appl. Nanosci., 2017, 7, 843-850.

11. Rout, Y., Behera, S., Ojha, A. K. and Nayak, P. L., Green synthesis of silver nanoparticles using Ocimum sanctum (Tulashi) and study of their antibacterial and antifungal activities. J. Microbiol. Antimicrob., 2012, 4, 103-109.

12. Shaik, M. R. et al., Plant extract assisted green synthesis of silver nanoparticles using Origanum vulgare L. extract and their microbicidal activities. Sustainability, 2018, 10, 913-927.

13. Khan, M. Z. H., Tareq, F. K., Hossen, M. A. and Roki, M. N. A. M., Green synthesis and characterization of silver nanoparticles using Coriandrum sativum leaf extract. J. Eng. Sci. Technol., 2018, 13, 158-166.

14. Singh, J., Mehta, A., Rawat, M. and Basu, S., Green synthesis of silver nanoparticles using sun dried tulsi leaves and its catalytic application for 4-nitrophenol reduction. J. Environ. Chem. Eng., 2018, 6, 1468-1474.

15. Singh, S., Saikia, J. P. and Buragohain, A. K., A novel green synthesis of colloidal silver nanoparticles (SNP) using Dillenia indica fruit extract. Colloid. Surf. B, 2013, 102, 83-85.

16. Saha, J., Begum, A., Mukherjee, A. and Kumar, S., A novel green synthesis of silver nanoparticles and their catalytic action in reduction of methylene blue dye. Sustain Environ. Res., 2017, 27, $245-250$. 
17. Ahmed, S., Saifullah, Ahmad, M., Swami, B. L. and Ikram, S., Green synthesis of silver nanoparticles using Azadirachta indica aqueous leaf extract. J. Rad. Res. Appl. Sci., 2015, 9, 1-7.

18. Azaizeh, H., Fulder, S., Khalil, K. and Said, O., Ethnomedicinal knowledge of local Arab practitioners in the Middle East Region. Fitoterapia, 2003, 74, 98-108.

19. Siva, M., Shanmugam, K. R., Shanmugam, B., Venkata, S. G., Ravi, S., Sathyavelu Reddy, K. and Mallikarjuna, K., Ocimum sanctum: a review on the pharmacological properties. Int. J. Basic Clin. Pharmacol., 2016, 5, 558-565.

20. Hemaiswarya, S., Kruthiventi, A. K. and Doble, M., Synergism between natural products and antibiotics against infectious diseases. Phytomedicine, 2008, 15, 639-652.

21. Mondal, S., Mirdha, B. R. and Mahapatra, S. C., The science behind sacredness of tulsi (Ocimum sanctum Linn.). Indian J. Physiol. Pharmacol., 2009, 53, 291-306.

22. Raseetha, V. S., Cheng, S. F. and Chuah, C. H., Comparative study of volatile compounds from genus Ocimum. Am. J. Appl. Sci., 2009, 6, 523-528.

23. Omoja, V. U. et al., The effects of combination of methanolic leaf extract of Azadirachta indica and diminazene diaceturate in the treatment of experimental Trypanosoma brucei brucei infection in rats. Asian. Pac. J. Trop. Med., 2011, 4, 337-341.

24. Blois, M. S., Antioxidant determinations by the use of a stable free radical. Nature, 1958, 181, 1199-1200.

25. Deka, H., Das, S., Lahan, J. P. and Yadav, R. N. S., In-vitro free radical scavenging, antioxidant and antibacterial activity of Azadirachta indica A. Juss. of Assam. Adv. Life Sci., 2013, 3, 1-4.

26. Bauer, K., Kirby, W., Sherris, J. and Truck, M., Antibiotic susceptibility testing by a standardized single disk method. Am. J. Clin. Pathol., 1966, 45, 493-496.

27. Yuan, Y. G., Peng, Q. L. and Gurunathan, S., Effects of silver nanoparticles on multiple drug-resistant strains of Staphylococcus aureus and Pseudomonas aeruginosa from mastitis-infected goats: an alternative approach for antimicrobial therapy. Int. J. Mol. Sci., 2017, 18(3), 569

28. Gao, X. et al., Toxicogenomic study in rat thymus of F1 generation offspring following maternal exposure to silver ion. Toxicol. Rep., 2014, 2, 341-350.

29. Kulkarni, N. and Muddapur, U., Biosynthesis of metal nanoparticles: a review. J. Nanotechnol., 2014, 1-8.

30. Jans, H., Liu, X., Austin, L., Maes, G. and Huo, Q., Dynamic light scattering as a powerful tool for gold nanoparticle bioconjugation and biomolecular binding studies. Anal. Chem., 2009, 81, 94259432.

31. Zanetti-Ramos, B. G. et al., Dynamic light scattering and atomic force microscopy techniques for size determination of polyurethane nanoparticles. Mater. Sci. Eng. C, 2009, 29, 638-640.
32. Khlebtsov, B. N. and Khlebtsov, N. G., On the measurement of gold nanoparticle sizes by the dynamic light scattering method. Colloid J., 2011, 73, 118-127.

33. Tscharnuter, W., Photon correlation spectroscopy in particle sizing. In Encyclopedia of Analytical Chemistry (ed. Meyers), John Wiley \& Sons Ltd, Chichester, 2000, pp. 5469-5485.

34. Evanoff Jr, D. D. and Chumanov, G., Synthesis and optical properties of silver nanoparticles and arrays. Chem. Phys. Chem., 2005, 6, 1221-1223.

35. Koppel, D. E., Analysis of macromolecular poly dispersity in intensity correlation spectroscopy: the method of cumulants. J. Chem. Phys., 1972, 57, 4814-4820.

36. Berne, B. J. and Pecora, R., Dynamic Light Scattering: with Applications to Chemistry, Biology and Physics, Dover, New York, USA, 2000.

37. Young, I. S. and Woodside, J. V., Antioxidants in health and disease. J. Clin. Pathol., 2001, 54, 176-186.

38. Halliwell, B. and Gutteridge, J. C., The definition and measurement of antioxidants in biological systems. Free Radic. Biol. Med., 1995, 18, 125-126.

39. Halliwell, B. and Gutteridge, J. M., Free Radicals in Biology and Medicine, Clarendon Press, Oxford, 1989, 2nd edn.

40. Cai, Y., Luo, Q., Sun, M. and Corke, H., Antioxidant activity and phenolics compounds of 112 traditional Chinese medicinal plants associated with anticancer. Life Sci., 2004, 74, 2157-2184.

41. Pitchaon, M., Suttajit, M. and Pongsawatmanit, R., Assessment of phenolic content and free radical-scavenging capacity of some Thai indigenous plants. Food Chem., 2007, 100, 1409-1418.

42. Balasundram, N., Sundram, K. and Samman, S., Phenolic compounds in plants and agri-industrial by-products: antioxidant activity, occurrence and potential uses. Food Chem., 2006, 99, 191-203.

43. Mistry, K. S., Sanghvi, Z., Parmar, G. and Shah Samir, The antimicrobial activity of Azadirachta indica, Mimusops elengi, Tinospora cardifolia, Ocimum sanctum and $2 \%$ chlorhexidine gluconate on common endodontic pathogens: an in vitro study. Eur. J. Dentist., 2019, 8, 172-177.

ACKNOWLEDGEMENT. We thank the Department of Biotechnology, Rama Devi Women's University, Bhoi Nagar, Bhubaneswar, Odisha, India.

Received 8 December 2018; revised accepted 17 June 2019

doi: $10.18520 / \mathrm{cs} / \mathrm{v} 117 / \mathrm{i} 8 / 1300-1307$ 